\title{
Sampling strategies for monitoring lameness in dairy cattle
}

\author{
D. C. J. Main, ${ }^{1}$ Z. E. Barker, K. A. Leach, N. J. Bell, H. R. Whay, and W. J. Browne \\ University of Bristol Veterinary School, Langford, Somerset, BS40 5DU, United Kingdom
}

\begin{abstract}
Evaluating the prevalence of lameness within herds of dairy cattle is important for management and certification purposes; however, sampling strategies that could reduce the time taken for an assessment would be valuable. The prevalence of lame and severely lame cows on 224 United Kingdom dairy farms was available for analysis. Presence of more than 1 severely lame cow on a farm was a useful indication of a lameness problem. The vast majority (80\%) of the 182 farms that had $\geq 1$ severely lame cow present had an overall lameness prevalence $>25 \%$, whereas only $24 \%$ of the 42 farms that had no severely lame cows had an overall prevalence $>25 \%$. Information was available on individual milking order through the parlor on the day of the lameness assessment. On 37 farms where cows were housed in a group, lameness prevalence was $11.9 \%$ greater in the last third compared with the first third of the milking order. For 36 herds that were larger than 100 cows, sampling a maximum of 100 cows from the middle of the milking order produced an estimate of prevalence within $5 \%$ of the true prevalence on $83 \%$ of farms. A reasonable sampling strategy may, therefore, be to observe up to 100 cows from the middle of the milking order. Also, presence of severely lame cows at the end of milking may be useful for identifying those farms likely to benefit from further support.
\end{abstract}

Key words: lameness, sampling strategy, dairy cow

\section{INTRODUCTION}

Formulating optimum strategies for monitoring lameness in dairy cattle requires a consideration of the potential benefits and practical realities of different possible approaches. Assessing lameness by viewing the entire milking herd as the cows leave the parlor is a long-established method of lameness detection that ensures minimal disruption (Whay, 2002). In addition to the immediate welfare benefits of this lack of disruption, cows are more likely to walk at a normal pace,

Received June 19, 2009.

Accepted January 4, 2010.

${ }^{1}$ Corresponding author: d.c.j.main@bris.ac.uk which is important for lameness assessment. Observing the entire herd can be very time consuming if the herd is large. This problem was identified by Thomsen (2009), who suggested that observation of an arched back in cows standing in the housed environment was a rapid screening method for lameness.

Although previous studies examined the reliability of some different scoring systems (March et al., 2007; Thomsen et al., 2008; Channon et al., 2009), few addressed the question of sampling in relation to lameness assessment. Previous studies assessed the entire herd to determine a herd-level prevalence for dairy cattle lameness (Huxley et al., 2004; Haskell et al., 2006; Rutherford et al., 2009). The need for further information on optimum sample size for welfare assessment in cattle was identified (Winckler et al., 2003). In discussions of the costs associated with welfare assessment, some have advocated reduction in sample size as a mechanism for reducing costs (Sørensen et al., 2007). These authors assessed welfare of dairy cows in a robotic milking system using a representative sample of cows, but did not specify how many cows or how they were chosen. Few studies examined different possible sampling strategies in farm animal welfare assessment. Waiblinger and Menke (2003) compared the whole-herd data collated for avoidance tests and then randomly divided it into 2 samples. Only moderate correlations between the different sampling approaches were found, and it was suggested that a smaller sample size reduced reliability and validity. As far as we are aware, no previous studies explored the optimum sampling strategy for monitoring lameness.

As with any other type of welfare-relevant variable, lameness assessments may be conducted for a variety of reasons (Main et al., 2003). Farmers need to assess which cows need to be treated and may wish to monitor the effect of husbandry changes. External assessors may use assessments as part of a certification tool that enables producers to be members of assurance schemes or to make specific welfare claims, or to achieve benchmarking of farms against others. The purpose for which lameness assessment is used will influence the choice of the optimum sampling methodology. A management tool that can monitor the effect of husbandry changes needs to be used at relatively frequent intervals. Hence, 
Table 1. Definitions of lameness scoring categories ${ }^{1}$

\begin{tabular}{ll}
\hline Score & Description \\
\hline 0 & $\begin{array}{c}\text { Sound: walks confidently, with even weight on all } 4 \text { feet; "tracks up" (hind feet in prints of fore feet; } \\
\text { best seen from the side); no swinging of legs inwards or outwards (best seen from behind). } \\
\text { Imperfect locomotion: may walk cautiously, possibly because of tenderness; or does not track up; } \\
\text { or legs swing out or in but no obvious limp. } \\
\text { Lame: definite limp (foot fall uneven, dew claws on affected limb do not drop as far) or arched spine. A favored limb } \\
\text { will move more quickly than the lame limb. Speed of walk not noticeably affected. } \\
\text { Severely lame: cannot walk as fast as a brisk human pace; shows obvious signs of limb pain } \\
\text { (e.g., reluctant to bear weight, very obvious shifts in body posture). }\end{array}$ \\
\hline
\end{tabular}

${ }^{1}$ Method described previously by Stokes et al. (2008).

the optimum sampling strategy for management applications would be the method that is practically possible and best represents the overall prevalence on a farm. In contrast, a certification assessment needs to produce a robust, transparent assessment that does not wrongly label producers. In this case, the result may be a binary response; for example, does the lameness level exceed a predefined acceptable threshold value? A risk-based approach that predicts farms that likely have higher levels of lameness may be valuable to management or certification applications (Capdeville and Veissier, 2001).

A previously acknowledged complication with selecting a sample of cows to assess as they leave the parlor is that the order of milking may be associated with lameness. Previous studies that examined milking order for cows at pasture showed that lame cows more likely went through the parlor toward the end of the milking order (Sauter-Louis et al., 2004; Walker et al., 2008).

This paper considers possibilities for making lameness scoring easier and less time consuming when the aim is to give a snapshot view of prevalence on the farm. The study aimed to define an optimum sampling strategy for assessing lameness in dairy cattle. An optimum strategy should produce an unbiased result with a low level of uncertainty but also be feasible to use given potential time constraints. The study considered the optimum position within the milking order to sample cows. Finally, a risk-based approach was explored by examining the reliability of using the presence of severely lame cows as an indicator of farms with overall high levels of lameness.

\section{MATERIALS AND METHODS}

\section{Data Collection}

Visits were made to 224 dairy farms between October 2006 and May 2007. Each farm was visited by one of 4 researchers. Farmers were recruited through 4 United Kingdom milk companies and via direct telephone contact to participate in a larger intervention study that was designed to test different motivational strategies.
The recruitment criteria for the intervention study were a total herd size $>35$ cows and an intention to continue dairying for the next 4 yr. Farms were located in southern and central England and south and west Wales. A more detailed description of the farms is published elsewhere (Barker et al., 2010).

All cows in the milking herd at the time of the visit were scored using the 4-point locomotion score (Table 1) described by Stokes et al. (2008), which was developed from that used by Whay et al. (2003). Cows with score 2 or 3 were described as lame. Cows were locomotion scored either as they exited the parlor or, on farms where 1) the parlor type or exit-way made it too difficult to observe the cows walking freely, 2) the cows did not have clear visible identification, or 3 ) herd size was particularly small, in a holding yard. The researchers were initially trained by 1 experienced scorer of locomotion. They continued to participate in regular group scoring sessions during the data collection period to minimize potential variation among the locomotion scores recorded on different farms. Agreement between observers was tested at the end of the data collection period by the 4 observers all scoring the same cows on videos. Percentage agreement and Kappa values were calculated for each researcher compared with each of the other 3 researchers.

For 67 out of the 224 farms, a record was made of the order that the cows left the parlor (milking order) on the day of lameness assessment. Therefore, each cow was allocated a number between 1 and $n$ (where $n=$ the number of cows being milked) representing milking order. On 37 of the 67 farms, cows were housed and milked all in 1 group. Cows on these farms were able to choose the order they entered the parlor. On the remaining 30 farms, cows were housed in different groups and there were some restrictions of the order cows were able to enter the parlor. From this data set, whole-herd lameness statistics were calculated for each individual farm. The concerns were with lameness prevalence (percentage score 2 or 3 ) and severe lameness prevalence (percentage score 3 ). The values were considered from the whole herd as true prevalences 
for comparison with our sampling schemes. It should be recognized that because of the subjective method and single assessment, these are only true within the limits of observer reliability and repeatability and time of assessment; however, this does not affect the value or validity of comparison with subsamples of the same data set for the purposes of investigating the result of using different sampling strategies. The sampling was achieved simply by taking subsamples (by computer) from the whole-herd data set for each farm to mimic potential sampling schemes and produce estimates of herd-level lameness that were compared with our true herd-level lameness.

\section{Data Modeling}

On the 67 farms for which both milking order and lameness assessment data were available, the effect on the estimated prevalence of using different theoretical sampling strategies was assessed. For defining a sampling scheme that resulted in a sufficient sample, samples were used around the middle of the herd milking order. For the purposes of this investigation, a sufficient sample was defined as the number of cows for which all subsequent prevalence estimates for that herd were $<5 \%$ different from the true prevalence for the herd. Prevalence from the sampled population was derived by calculating a cumulative prevalence as each additional cow was assessed, starting from the middle cow. So for a 100-cow herd, the prevalence among the initial 10 cows included cows from milking order number 45 to 54, the next prevalence was calculated from 11 cows (cows from order number 44 to 54), and then from 12 cows (order number 44 to 55), and so on.

A regression curve was then generated to predict a typical sample size needed to give an estimate of prevalence within $5 \%$ of the true prevalence for any given herd size. This typical sample size was used to compare alternative sampling approaches for the data from the 67 farms. This was achieved by calculating the prevalence on each farm if the required sample numbers of cows were taken from the start, the middle, or the end of milking. For example, on a farm with 100 cows, the typical sample size needed to get within $5 \%$ of true prevalence was 49 cows. In this case, the prevalence from the sampled group taken from the start of milking order was calculated from cow number 1 to 49, for the middle sample from cow 25 to 74 , and for the end of milking sample from cow 51 to 100 .

Last, using the same typical sample size, the lameness prevalence was calculated from 1,000 random samples taken from the entire milking order. These samples were generated by taking random samples of the typical sample size number of cows from the whole herd without replacement 1,000 times. An estimate of the farm lameness prevalence was calculated for each random sample. For each farm, the upper and lower $95 \%$ confidence interval of the lameness prevalence was calculated from samples taken from cows in random milking order.

In addition, a potential strategy of using presence of severely lame cows on the farm as a predictor of high levels of overall lameness (i.e., score 2 and 3) was investigated using the information from the all 224 farms. The lameness prevalence (score 2 and 3 ) on those farms with either no severely lame cows, any (i.e., 1 or more) severely lame cows, or $>5 \%$ severely lame cows was assessed. For the 67 farms where milking order information was available, a strategy of identifying severe lameness within the last 20 cows leaving the parlor was examined. Here, the overall prevalence of lameness was reported for those farms with or without at least 1 severely lame cow within the last 20 cows leaving the parlor.

\section{Data Analysis}

For analysis the milking order was converted into 1) percent rank (i.e., the rank of the cow's position in the milking order as a percentage of the total number of cows observed on that farm) and 2) the first, middle, and last third (i.e., groups) of the milking order. The association between lameness score and percent rank was analyzed by the Kruskall-Wallis nonparametric test and the association between the lameness score and the relevant thirds (first, middle, and last) was analyzed using chi-square. The overall effect of whether cows were group housed in separate groups on the lameness prevalence in the first, middle, and last third of the milking order was also analyzed using chi-square. The difference between the sampled and true lameness prevalence at the start, middle, or end of milking was examined using the nonparametric repeated measures Friedman test. The statistical package $\mathrm{R}$ (version 2.7, http://www.R-project.org; R Foundation for Statistical Computing, Vienna, Austria) was used for generation of random samples, and all other analysis was conducted using SPSS (version 14.0, SPSS Inc., Chicago, IL).

\section{RESULTS}

\section{Effect of Observed Milking Order on Lameness Prevalence}

For the 67 farms for which milking order was available, 8,776 cows were assessed for lameness. The number of cows assessed during milking on each farm ranged from 29 to 268 (mean: 131.4 cows). The numbers of cows 


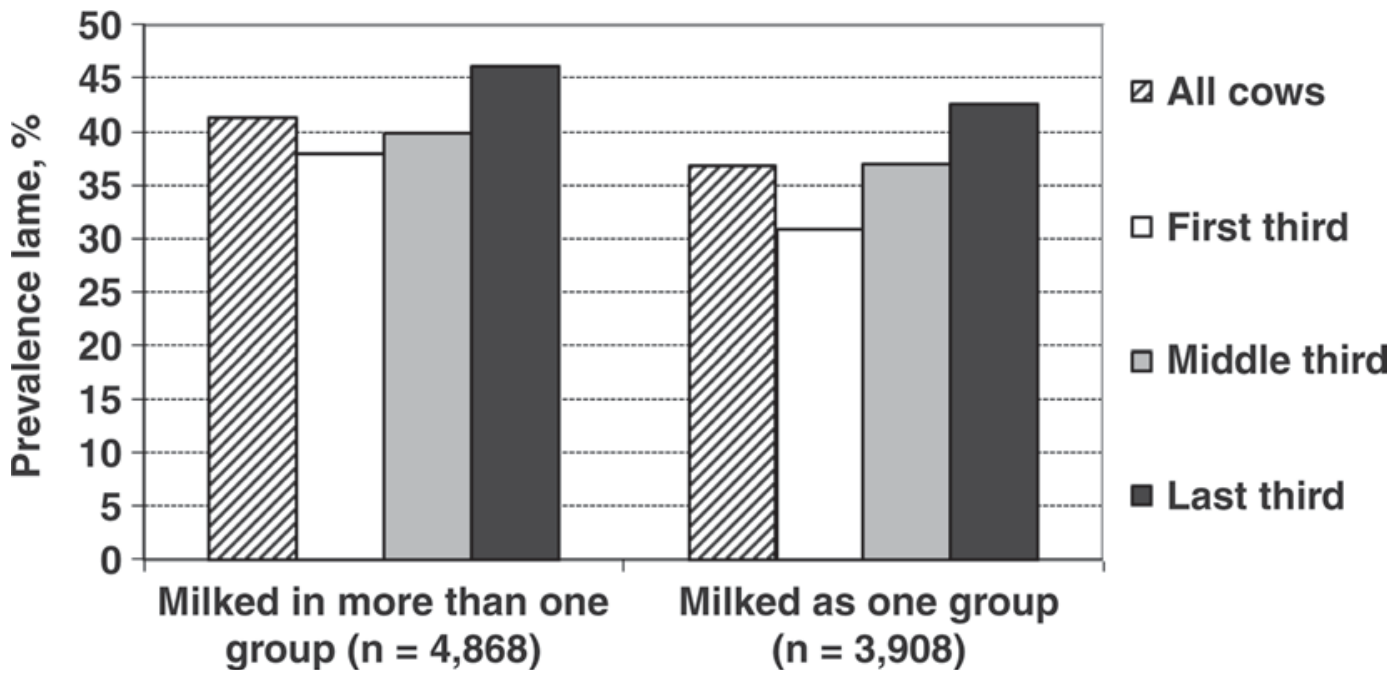

Figure 1. The overall prevalence of lame cows (score 2 and 3) on 30 farms that housed and milked their cows in more than 1 group and 37 farms that housed and milked their cows as 1 group. Prevalence was calculated either from all cows or from the first, middle, or last third as they left the parlor.

with scores $0,1,2$, and 3 were $436,4,910,2,895$, and 535 , respectively. For allocation of cows as not lame (score 0 or 1 ) or lame (score 2 or 3 ), agreement between pairs of observers ranged from 83.9 to $96.8 \%$ [kappa values: 0.67 (moderate) to 0.93 (good)]. Repeatability within observer, tested by rescoring the same videos, showed agreement between 90.6 and 100\% with kappa values from 0.81 to 1.00 .

The overall lameness (score 2 and 3 ) prevalence in the 8,776 cows examined was $39.1 \%$. There was an association between percent rank milking order and lameness score as cows walked out of the parlor $(P<$ 0.001, Kruskall-Wallis) on the 67 farms. The median ( \pm interquartile range) percent rank milking order for cows with lameness score $0,1,2$, and 3 was $49( \pm 47)$, $47( \pm 50), 53( \pm 50)$, and $63( \pm 50)$, respectively. The lameness prevalence within the cows that came through in the first, middle, and last third of the milking order was $34.5,38.5$, and $44.1 \%$, respectively $(P<0.001$; chisquare).

For each housing system (i.e., housed together or in separate groups), the overall lameness prevalence (score 2 and 3 ) and severe lameness prevalence (score 3 only) calculated from the first, middle, and last third of the milking order are shown in Figures 1 and 2, respectively. For both types of farms, lameness and severe lameness prevalence was associated (chi-square; $P<0.001$ ) with the position (i.e., first, middle, or last third) in the milking order. In addition, for both lameness and severe lameness prevalence, the proportion of the affected cows within the middle third was more similar to the overall prevalence than either the first or last third, irrespective of the grouping system. Cows housed in 1 group showed a larger difference in prevalence (11.9\%) between first and last third of milking order compared with those housed in $>1$ group $(8.2 \%)$. This same pattern of difference between first and last third prevalence was observed in the severely lame cows, with a difference of $6.5 \%$ between first third and last third in the single group compared with $3.6 \%$ for multiple group herds.

\section{Sample Size for Sufficient Estimate of Lameness Prevalence}

The number of cows needed for observation from the middle of milking order to get within $5 \%$ of the true lameness was calculated on each of the 67 farms and is shown in Figure 3. For farms up to 100 cows, the number of cows needed for observation ranged up to a maximum of 62 . For farms with $>100$ cows, in 30 out of $36(83 \%)$ cases it was not necessary to observe $>100$ cows to be within $5 \%$ of the true prevalence.

The line of best fit (i.e., a typical farm) that could be used to predict how many cows would be needed for a given herd size is shown in Figure 3. The quadratic equation $\left(\mathrm{r}^{2}=0.31 ; P<0.001\right)$ for the line of best fit was as follows: sample size $=-0.001 \mathrm{n}^{2}+0.498 \mathrm{n}+$ 6.785 , where $\mathrm{n}=$ number of cows in milking herd. This model was used to define the sample size for a typical farm across a range of herd sizes (Table 2). Using average sample size is similar to using a power of 0.5 , and this sample size was used for the exercise of comparing samples from different positions in the milking order. For a commonly used power of 0.8 , the sample size would need to be increased. 


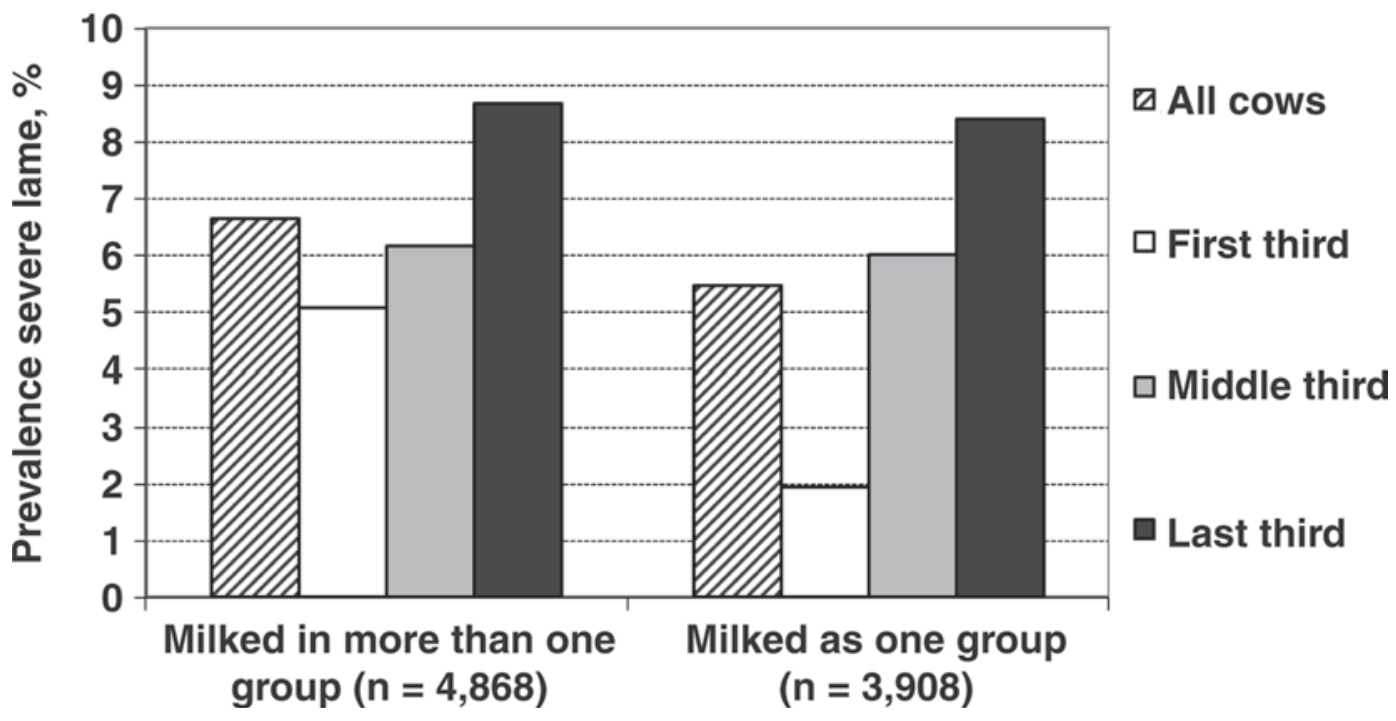

Figure 2. The overall prevalence of severely lame cows (score 3) on 30 farms that housed and milked their cows in more than 1 group and 37 farms that housed and milked their cows as 1 group. Prevalence was calculated either from all cows or from the first, middle, or last third as they left the parlor.

Using the number of cows defined by this typical sampling strategy (Table 2), the lameness prevalence when sampling from the start, middle, and end of the milking order was calculated and the difference in the sampled prevalence vs. true prevalence is shown in Figure 4 . The sample from the middle of the milking order was most similar to the true prevalence. The difference between the sampled and true lameness prevalence was associated (Friedman test; $P<0.001$ ) with the sampling position, with sampling from the end being an overestimate and sampling from the start being an underestimate.

When randomly sampling across the entire milking order, the upper and lower 95\% confidence interval width was consistent across all the 67 farms (Figure 5).

Table 2. Sampling based on the quadratic equation that best explained the sample size needed to get within $5 \%$ of the true prevalence based on sampling cows from the middle of the milking order

\begin{tabular}{lc}
\hline Herd size & Sample size $^{1}$ \\
\hline 25 & 20 \\
50 & 30 \\
75 & 40 \\
100 & 49 \\
125 & 57 \\
150 & 64 \\
200 & 75 \\
225 & 79 \\
250 & 82 \\
275 & 84 \\
300 & 85 \\
\hline
\end{tabular}

${ }^{1}$ Sample size $=-0.001 \mathrm{n}^{2}+0.498 \mathrm{n}+6.785$, where $\mathrm{n}=$ number of cows in milking herd.
Across all the farms, the maximum upper confidence interval was $11.5 \%$ above the true farm prevalence. Using the random sampling technique, $79 \%$ of samples were within $5 \%$ of the true prevalence. For comparison, sampling cows contiguously around the middle of the milking order and assessing the same number of cows is shown in Figure 5. The middle sampling method (using the same number of cows) resulted in a maximum difference of $10.6 \%$ from the true prevalence, with 49

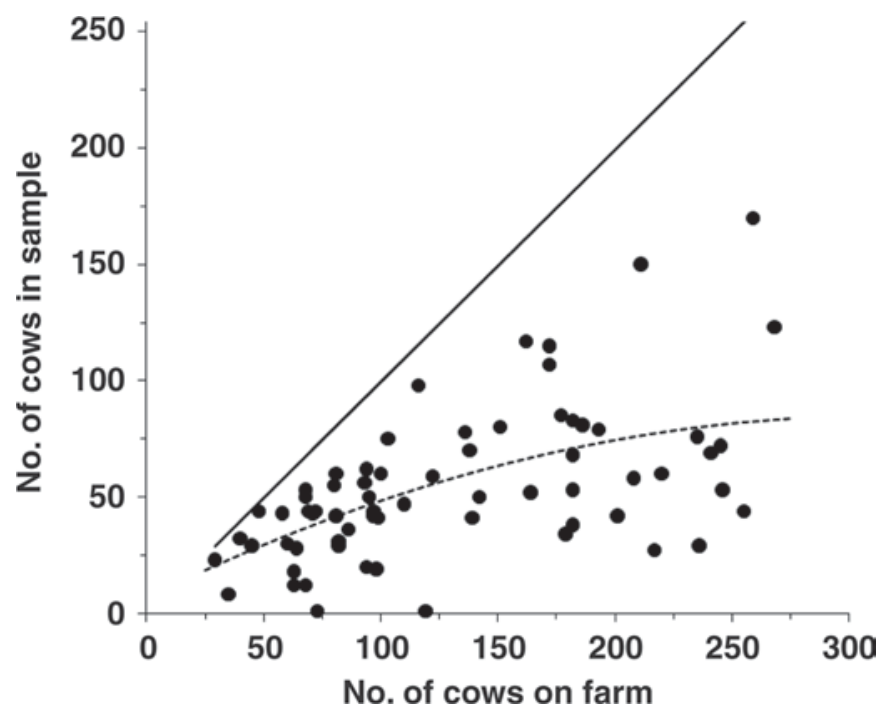

Figure 3. Number of cows within a sample $(\bullet)$ needed to produce a lameness prevalence within $5 \%$ of the true prevalence on 67 farms. Solid line represents the sample size if all cows were needed on each farm. Dotted line represents a typical farm (i.e., the line that best predicts the number required for each farm). 


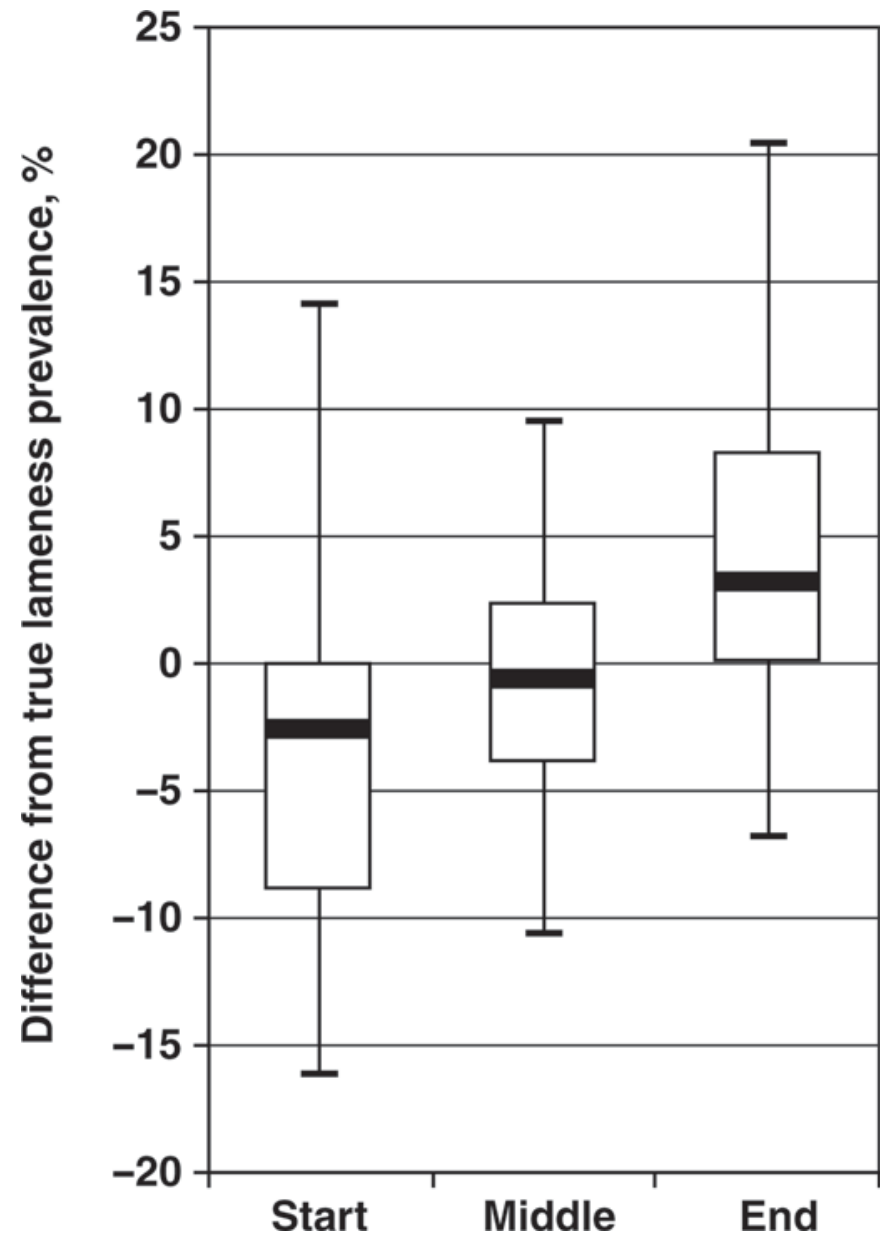

Figure 4. The minimum, median, maximum, and interquartile ranges for the difference between the true lameness prevalence and the prevalence in a sample calculated from contiguous cows at the start, middle, or end of the milking order on 67 farms. Sample size for each farm is based on the sampling strategy in Table 2.

of the $67(73 \%)$ farms sampled by this method being within $5 \%$ of the true prevalence. Sampling from cows at the start or end of milking resulted in a maximum difference of 16.2 and $20.4 \%$, respectively (Figure 4 ). Only 38 farms (57\%) sampled from either the start or end of the milking order were within $5 \%$ of the true prevalence.

\section{Severe Lameness as a Predictive Risk Factor}

The distribution of lameness on those farms with either no, any (i.e., 1 or more), or $>5 \%$ severely lame cows present is shown in Figure 6. Of 224 farms assessed, 42 farms had no severely lame cows. Of these farms, only $10(24 \%)$ had an overall lameness prevalence of more than $25 \%$. For the 182 farms with at least 1 severely lame cow present, $146(80 \%)$ farms had $>25 \%$ lameness overall. Similarly, on those 88 farms with $>5 \%$ severely lame, 84 farms $(95 \%)$ had $>25 \%$ lameness overall.

Furthermore, based on the milking order results, severely lame cows were more likely observed at the end of milking. For the 67 farms for which milking order was available, 52 farms had at least 1 severely lame cow. If only the last 20 cows leaving the parlor were observed, then 40 of these 52 farms would have been highlighted by this method. The lameness prevalence on farms identified as at risk or not by observing the last 20 cows on these 67 farms is shown in Figure 6. For farms with no severely lame cows in the last 20 cows, only $26 \%$ of farms $(7 / 27)$ had $>25 \%$ overall lameness, whereas for farms with 1 or more severely lame cow observed in the last 20 cows, $93 \%$ of farms (37/40) were above this threshold.

\section{DISCUSSION}

This study outlined some potential approaches to sampling that may confer significant practical advantages because scoring the whole herd may be too time consuming for assessors who need to assess many different aspects of a farm system. It is important to recognize that the ideal approach to assess the levels of lameness within a milking herd is to assess all cows, and as Rousing et al. (2001) pointed out, selection of sampling methods for operational welfare systems involves balancing reliability and costs.

Sampling-based approaches will increase the possibility of assessment error. This error is in addition to the observer error associated with the current method of lameness assessment (March et al., 2007). Kujala et al. (2008) examined automatic monitoring systems for lameness. This would certainly remove subjectivity and could be a useful management tool for those farms able to afford the investment.

As expected, there was a relationship between lameness and position in milking order, with lame, especially severely lame, cows being milked toward the end of milking, which meant that the position of the sample group within the milking order affected the apparent prevalence of lameness. Assuming that only a proportion of cows can be observed and no other information is available before an assessment, it is reasonable to suggest that observing cows in the middle of the milking order likely yields a more accurate value than observing cows at the start or end of milking.

A sampling paradigm was investigated (Table 2). Sampling from the middle order of cows produced a sampled lameness prevalence within $5 \%$ of true mean in $73 \%$ of the farms. A theoretical random sampling strategy from the entire milking order using the same number of cows would result in $79 \%$ of farms assessed 


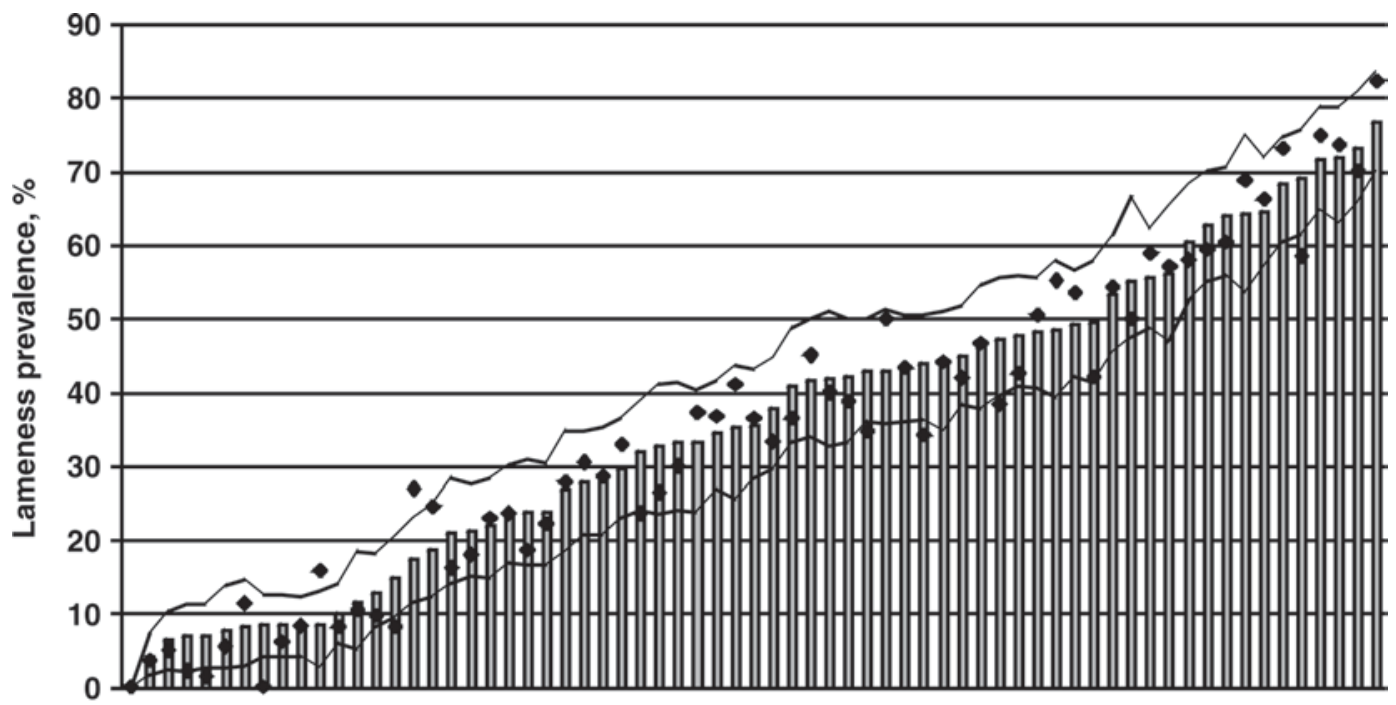

Farms ordered by true lameness prevalence

$\square$ True lameness prevalence from all cows - Upper and lower $\mathrm{Cl}$ from random sample

- Sample from middle of milking order

Figure 5. Three measures of lameness prevalence for 67 farms: the upper and lower 95\% CI of lameness prevalence obtained from a random sample of cows (lines), prevalence estimated from a single sample of cows taken from the middle of the milking order (symbols), and true prevalence from all cows (bars). Sample size for random 1,000 samples and middle-order single sample based on the sampling strategy in Table 2.

being within $5 \%$ of the true prevalence. Using the method described by Dohoo et al. (2003), a random sampling approach to estimate herd-level prevalence in herds up to 54 cows was used by Dippel et al. (2009). Applying the same method of sampling to a herd size of 100 cows would have required 65 cows, whereas in our study 49 cows were used for the random sampling approach. Hill et al. (1997) randomly sampled within a herd to estimate the herd-level prevalence of lameness in dairy goats. Assuming a prevalence of $50 \%$, a $95 \%$ confidence interval, and $10 \%$ accuracy, the sample size needed for herds ranging from 350 to 450 was between 75 and 78 goats per farm. Because random sampling during milking conveys limited practical benefits and because the assessor was present throughout the milking, a simpler alternative sampling strategy based on a maximum of 100 cows taken from the middle of milking was investigated in this study. This approach meant

- No severely lame cows (42/224 farms)

- One or more severely lame cow (182/224 farms)

- More than $5 \%$ severely lame cows (88/224 farms)

$\circ$ No severely lame cows in last 20 cows out of parlor (27/67 farms)

$\triangle$ One or more severely lame cow in last 20 out of parlor $(40 / 67$ farms)

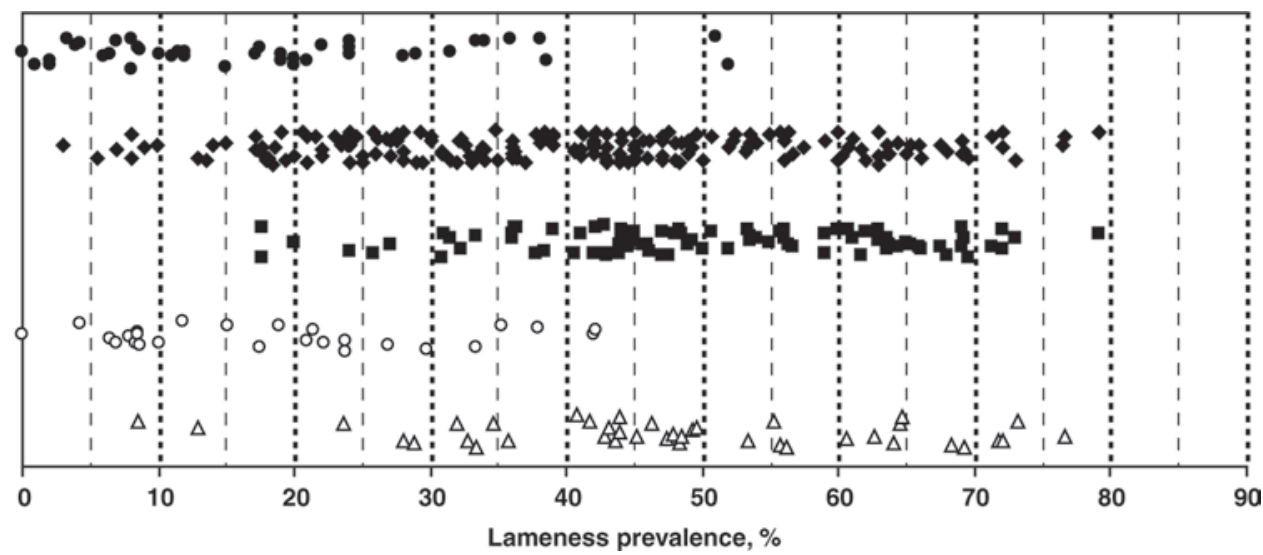

Figure 6. The herd prevalence of lameness (score 2 and 3) on 224 farms with different numbers of severely lame cows (score 3 ) in the whole milking herd (score 3) and on 67 farms where different numbers of severely lame cows were observed in the last 20 cows leaving the parlor. 
Table 3. Implications of applying different monitoring strategies to either a management or certification application ${ }^{1}$

\begin{tabular}{lll}
\hline $\begin{array}{l}\text { Monitoring } \\
\text { strategy }\end{array}$ & Description (increasing intensity) & Possible management implications \\
\hline $\begin{array}{lll}\text { Informal } \\
\text { monitoring }\end{array}$ & $\begin{array}{l}\text { Informal monitoring of all cows on a } \\
\text { daily basis for individual cows that } \\
\text { are likely to benefit from treatment. }\end{array}$ & $\begin{array}{l}\text { Good practice on most farms because } \\
\text { informal monitoring is a common } \\
\text { method to ensure that individual } \\
\text { cows receive appropriate care. }\end{array}$
\end{tabular}

Risk-based approach

Whole-herd assessment

Identification of any cows with severe lameness, especially at end of milking; would classify the farm as at risk of higher overall lameness prevalence.

Sampling from middle of milking order

A maximum sample size of 100 cows taken from cows in middle portion of milking order. (For farms with $<100$ cows, this would be the true prevalence. For larger farms, the prevalence would be within $5 \%$ of true prevalence on more than $80 \%$ of farms.)

Whole herd assessed as cows exit parlor.
Farms identified as at risk likely benefit from additional support and advice, including more effect of any husbandry changes.

For most farms, sampling up to 100 cows would be sufficient to monitor the effect of husbandry changes, although not all lame cows would be formally identified for treatment in larger herds.

Prevalence generated should allow the producer to monitor effect of husbandry changes and identify or monitor the lameness of individual lame cows. intensive monitoring to assess
Possible certification implications

Assessor can verify that cows observed lame on a visit have received appropriate care. Treatment records can be required to demonstrate appropriate care.

Certification schemes can use this risk-based approach to identify farms that may need additional management support.

Potential sampling error in the larger herds means that certification schemes could use this approach only for identifying farms needing support and not as a basis for possible penalty.

If a certain level was exceeded, schemes could insist upon remedial husbandry changes, formulation of written action plans, seeking veterinary advice, or regular formal monitoring of lameness.

${ }^{1}$ The implications assume that the assessor is standardized with other assessors and is consistent among assessments.

that $83 \%$ of farms with $>100$ cows yielded a sampled prevalence within $5 \%$ of true prevalence when only 100 cows were assessed irrespective of herd size from the middle of the milking order. It is unclear whether this approach would be valid for farms larger that the study maximum of 268 .

Previous consultations reported that $80 \%$ of experts considered that action should be taken when herd prevalence for lameness exceeds only $14 \%$ on farm (Whay et al., 2003). This study suggests that presence of severely lame cattle may be a mechanism for identifying those farms that may benefit from further investigation or support. Because there are fewer severely lame cows than lame cows on farms, defining the true prevalence of severely lame cows on a farm would require at least as many cows as those needed for lameness prevalence. Because severely lame cows may be easier to observe during milking, a risk criterion based simply on observing a single severely lame cow near the end of milking may have value for nonresearch applications. An assessor could obtain this initial information quite easily. An alternative method of identifying severely lame cows could be the observation of an arched back in the housing environment used for rapid screening by Thomsen (2009).

The integration of these findings with possible management and certification applications of lameness assessment is shown in Table 3. The informal monitoring of cows that occurs during milking is the common method of identifying those cows that might benefit from individual treatment. This does not provide the herd-level information useful for assessing either the overall suitability of lameness management on a farm or the effect of husbandry changes on lameness prevalence. For each subsequent option (risk-based, sampling, or whole-herd), the time taken or resource needed would increase along with the increased opportunities for application.

Finally, it may be possible to reduce the sample size by using a sequential statistical modeling approach. This has similarities with the risk-based approach in that it is useful for discovering whether a prevalence is above or below a specified threshold. By examining the scores of the sample as they are collected, it may be possible to stop sampling early when the data indicated that the decision as to which side of the threshold the whole-herd prevalence lies was clear-cut. The statistical methodology needed to work out the stopping rule precisely during a visit would make this impractical to use with cows leaving a parlor, but some rough approximation calculated before a visit could be used. For example, with a herd of 100 cows and with a prevalence $>20 \%$, and if the first 10 cows were all lame, there would be reasonable confidence in getting another 10 
of the remaining 90 . If the first 20 were all lame, this would guarantee a prevalence of at least $20 \%$ and collecting further data would be pointless.

\section{CONCLUSIONS}

As anticipated, the position of a cow within the milking order was associated with lameness, with lame cows more likely present toward the end of milking. If a sampling strategy is used, then sampling from the middle of milking order on most farms would seem most appropriate. The proportion of the herd that needs assessment was examined for herds with up to 268 cows. To obtain reasonable estimates of prevalence, a simple paradigm of observing all cows, up to a maximum of 100 cows, provided a reasonable estimate of lameness. By observing the presence of severely lame cows, especially at the end of milking, farms that are most likely to benefit from assistance with their lameness management can be identified.

\section{ACKNOWLEDGMENTS}

This study was supported by the Tubney Charitable Trust (Reading, UK) and we thank them and the farmers involved for their cooperation.

\section{REFERENCES}

Barker, Z. E., K. A. Leach, H. R. Whay, N. J. Bell, and D. C. J. Main. 2010. Assessment of lameness prevalence and associated risk factors in dairy herds in England and Wales. J. Dairy Sci. 93:932-941.

Capdeville, J, and I Veissier.. 2001. A method of assessing welfare in loose housed dairy cows at farm level, focusing on animal observations. Acta Agric. Scand. A Anim. Sci. 51(Suppl. 30):6268.

Channon, A. J., A. M. Walker, T. Pfau, I. M. Sheldon, and A. M Wilson. 2009. Variability of Manson and Leaver locomotion scores assigned to dairy cows by different observers. Vet. Rec. 164:388 392

Dippel, S., M. Dolezal, C. Brenninkmeyer, J. Brinkmann, S. March, U. Knierum, and C. Winckler. 2009. Risk factors for lameness in cubicle-housed Austrian Simmental dairy cows. Prev. Vet. Med. 90:102-112.

Dohoo, I. R., W. Martin, and H. Stryhn. 2003. Veterinary Epidemiologic Research. AVC Inc., Charlottetown, Prince Edward Island, Canada.

Haskell, M. J., L. J. Rennie, V. A. Bowell, M. J. Bell, and A. B. Lawrence. 2006. Housing system, milk production, and zerograzing effects on lameness and leg injury in dairy cows. J. Dairy Sci. 89:4259-4266
Hill, N. P., P. E. Murphy, A. J. Nelson, N. Mouttotou, L. E. Green, and K. L. Morgan. 1997. Lameness and foot lesions in adult British dairy goats. Vet. Rec. 141:412-416.

Huxley, J. N., J. Burke, S. Roderick, D. C. J. Main, and H. R. Whay. 2004. Animal welfare assessment benchmarking as a tool for health and welfare planning in organic dairy herds. Vet. Rec. 155:237239.

Kujala, M., M. Pastell, and T. Soveri. 2008. Use of force sensors to detect and analyse lameness in dairy cows. Vet. Rec. 162:365368.

Main, D. C. J., J. P. Kent, F. Wemelsfelder, E. Ofner, and F. A. M. Tuyttens. 2003. Applications for methods of on-farm welfare assessment. Anim. Welf. 12:523-528.

Main, D. C. J., H. R. Whay, L. E. Green, and A. J. F. Webster. 2003 Effect of the RSPCA Freedom Food scheme on the welfare of dairy cattle. Vet. Rec. 153:227-231.

March, S., J. Brinkmann, and C. Winkler. 2007. Effect of training on the inter-observer reliability of lameness scoring in dairy cattle. Anim. Welf. 16:131-133.

Rousing, T., M. Bonde, and J. T. Sørensen. 2001. Aggregating welfare indicators into an operational welfare assessment system: A bottom up approach. Acta Agric. Scand. A Anim. Sci. 51(Suppl. 30):53-57.

Rutherford, K. M. D., F. M. Langford, M. C. Jack, L. Sherwood, A. B. Lawrence, and M. J. Haskell. 2009. Lameness prevalence and risk factors in organic and non-organic dairy herds in the United Kingdom. Vet. J. 180:95-105.

Sauter-Louis, C. M., R. Chesterton, and D. U. Pfeiffer. 2004. Behavioural characteristics of dairy cows with lameness in Taranaki, New Zealand. N. Z. Vet. J. 52:103-108.

Sørensen, J. T., T. Rousing, S. H. Møller, M. Bonde, and L. Hegelund. 2007. On-farm welfare assessment systems: What are the recording costs? Anim. Welf. 16:237-239.

Stokes, J., Z. Barker, N. Bell, A. Bell, K. Leach, C. Maggs, D. Main, and H. R. Whay. 2008. Lameness in dairy cattle: Relationships between environments, animal based welfare measures and locomotion. Pages 49-52 in Proc. 15th Int. Symp. Conf. on Lameness in Ruminants, Kuopio, Finland. Savonia University of Applied Sciences, Kuopio, Finland.

Thomsen, P. T. 2009. Rapid screening method for lameness in dairy cows. Vet. Rec. 164:689-690.

Thomsen, P. T., L. Munksgaard, and F. A. Togersen. 2008. Evaluation of a lameness scoring system for dairy cows. J. Dairy Sci. 91:119 126.

Waiblinger, S., and C. Menke. 2003. Influence of sample size and experimenter on reliability of measures of avoidance distance in dairy cows. Anim. Welf. 12:585-589.

Walker, S. L., R. F. Smith, J. E. Routly, D. N. Jones, M. J. Morris, and H. Dobson. 2008. Lameness, activity time-budgets, and estrus expression in dairy cattle. J. Dairy Sci. 91:4552-4559.

Whay, H. R. 2002. Locomotion scoring and lameness detection in dairy cattle. 2002. In Pract. 24:444-449.

Whay, H. R., D. C. J. Main, L. E. Green, and A. J. F. Webster. 2003. Assessment of the welfare of dairy cattle using animal-based measurements: Direct observations and investigation of farm records. Vet. Rec. 153:197-202.

Winckler, C., J. Capdeville, G. Gebresenbet, B. Hörning, U. Roiha, M. Tosi, and S. Waiblinger. 2003. Selection of parameters for on-farm welfare-assessment protocols in cattle and buffalo. Anim. Welf. $12: 619-624$ 